\title{
Major Problems to the Clinical Reassessment of Celiac Disease in Elderly
}

\author{
Diana Deleanu ${ }^{1}$, Adriana Muntean ${ }^{1}$, Adrian Baican², Patrik Danciu ${ }^{3}$, Claudia Magurici ${ }^{3}$, Gabriel Samasca ${ }^{1, *}$ \\ ${ }^{1}$ Department of Allergology and Immunology, Iuliu Hatieganu University of Medicine and Pharmacy, Cluj-Napoca, Romania \\ ${ }^{2}$ Department of Dermatology, Iuliu Hatieganu University of Medicine and Pharmacy, Cluj-Napoca, Romania \\ ${ }^{3}$ Department of Internal Medicine, Regional Institute of Gastroenterology and Hepatology “Prof. Dr. Octavian Fodor”, Cluj-Napoca, Romania \\ *Corresponding author: Gabriel.Samasca@umfcluj.ro
}

Received May 01, 2015; Revised May 12, 2015; Accepted May 15, 2015

\begin{abstract}
Old age seems to be the greatest risk factor for celiac disease. Strict adherence to a gluten-free diet is difficult for these patients. We present the clinical reassessment in the case of a third age patient, with celiac disease under gluten-free diet and multiple related diseases.
\end{abstract}

Keywords: celiac disease, ischemic cardiopathy, depression

Cite This Article: Diana Deleanu, Adriana Muntean, Adrian Baican, Patrik Danciu, Claudia Magurici, and Gabriel Samasca, "Major Problems to the Clinical Reassessment of Celiac Disease in Elderly." International Journal of Celiac Disease, vol. 3, no. 3 (2015): 110-111. doi: 10.12691/ijcd-3-2-5.

\section{Introduction}

Celiac disease (CD) can be diagnosed at any age [1]. Some important complications include osteoporosis, iron and vitamin deficiencies and enteropathy-associated T-cell lymphoma were reported [2]. We report a CD patient in which a dietitian support is absolutely necessary.

\section{Case Report}

A 62-years-old patient known with CD for about 10 years without strict adherence to the diet in the past year, with chronic ischemic cardiopathy, with angina pectoris of effort, with left ventricular failure, with asthma, with advanced osteoporosis, was admitted in our medical unit for diarrhea (6 stools / day), weight loss (3-4kg / 6 months), asthenia, erythematous plaques, itchy, cracked on the dorsal hands, proximal (Figure 1).

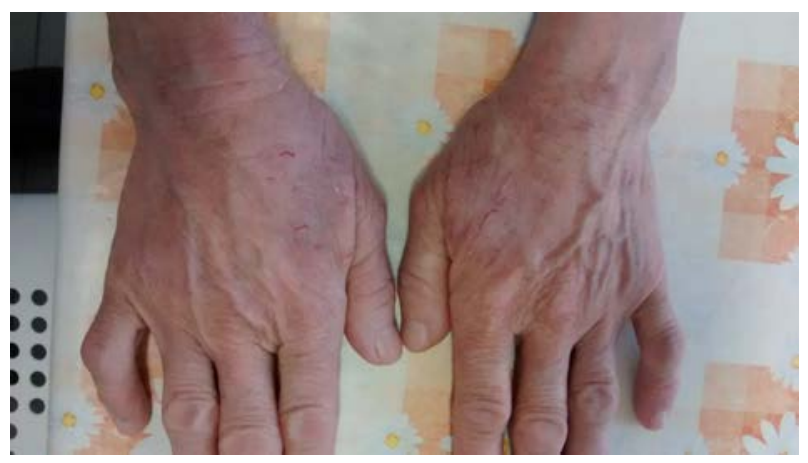

Figure 1. Dermatitis Herpetiformis?

Physical examination on admission showed a influenced general condition, erythema of the cheeks, dry skin, degenerative changes of the bilateral interphalangeal joints, blood pressure $=100 / 70 \mathrm{~mm} \mathrm{Hg}$, pulse rate $=60 /$ min, supple and elastic abdomen, epigastric and right hypochondrium tenderness.

We found WBC=3.20 [4-10 10*3/ $\mu 1]$, LYM=0.90 [1.5$410 * 10 * 3 / \mu \mathrm{l}], \mathrm{HGB}=10.3[11.7-16 \mathrm{~g} / \mathrm{dL})$, the blood cell analysis with anisocytosis, microcytic, ESR = 32 [2-7 $\mathrm{mm}]$, Magnesium = 1.56 [1.60-2.40 $\mathrm{mEq} / \mathrm{L}]$, Iron = 19 [50-170 / g / dL /]. The initial diagnosis of CD has been based on duodenal biopsy, which showed mucosal changes suggestive of villous atrophy. We determined at this clinical reassessment only IgA anti-tissue transglutaminase antibodies that were positive. Coproculture showed a negative result for Shigella, Salmonella, Yersinia. Rapid test for Clostridium was negative. Pulmonary function report showed severe obstructive ventilatory dysfunction on small pathways (Figure 2).

Prick test showed no cutaneous sensitization to inhaled and food tested allergens. Colonoscopic examination showed internal hemorrhoids. His suspected diagnosis of dermatitis herpetiformis was excluded. Abdominal ultrasonography showed biliary dyskinesia.

The diagnosis of our patients was CD, chronic ischemic cardiopathy, NYHA II left ventricular failure, stage III controlled asthma, advanced osteoporosis, iron deficiency anemia, internal hemorrhoids, hypomagnesemia, and depressive disorder

\section{Discussions}

CD has a cure - gluten free diet [3], therefore IgA antitissue transglutaminase antibodies was performed to our patient [4]. For the diarrheal stools and weight loss of our patient, we searched through stool analysis and 
Clostridium testing, bacterial species that can persist in the microbiota of CD patients [5] and we also searched, through biochemical exams, nutritional deficiencies that should be periodically studied in CD follow-up [6]. But what attracts attention is ischemic cardiomyopathy and depressive disorder. The association of CD in adults with chronic ischemic cardiomyopathy has been described in recent years only to persons under 30 years $[7,8]$ but never the people of the third age. The association would be fatal in some cases and the clinicians revealed the need for a rapid diagnosis of $\mathrm{CD}$ with nutritional deficiencies correction [9]. Unfortunately, about depressive disorder in this patient, we do not know much, the diagnosis was taken from another clinic after a psychiatric examination, but in recent years the medical literature draws attention on these psychiatric manifestations in CD [10,11]. Some authors have said that depression should more common in patients with CD [12], we say that to our patient depressive disorder could have a variety of causes including associated diseases or gluten-free diet. But on the background of gluten-free diet, we believe that the support of a psychiatrist is absolutely necessary.

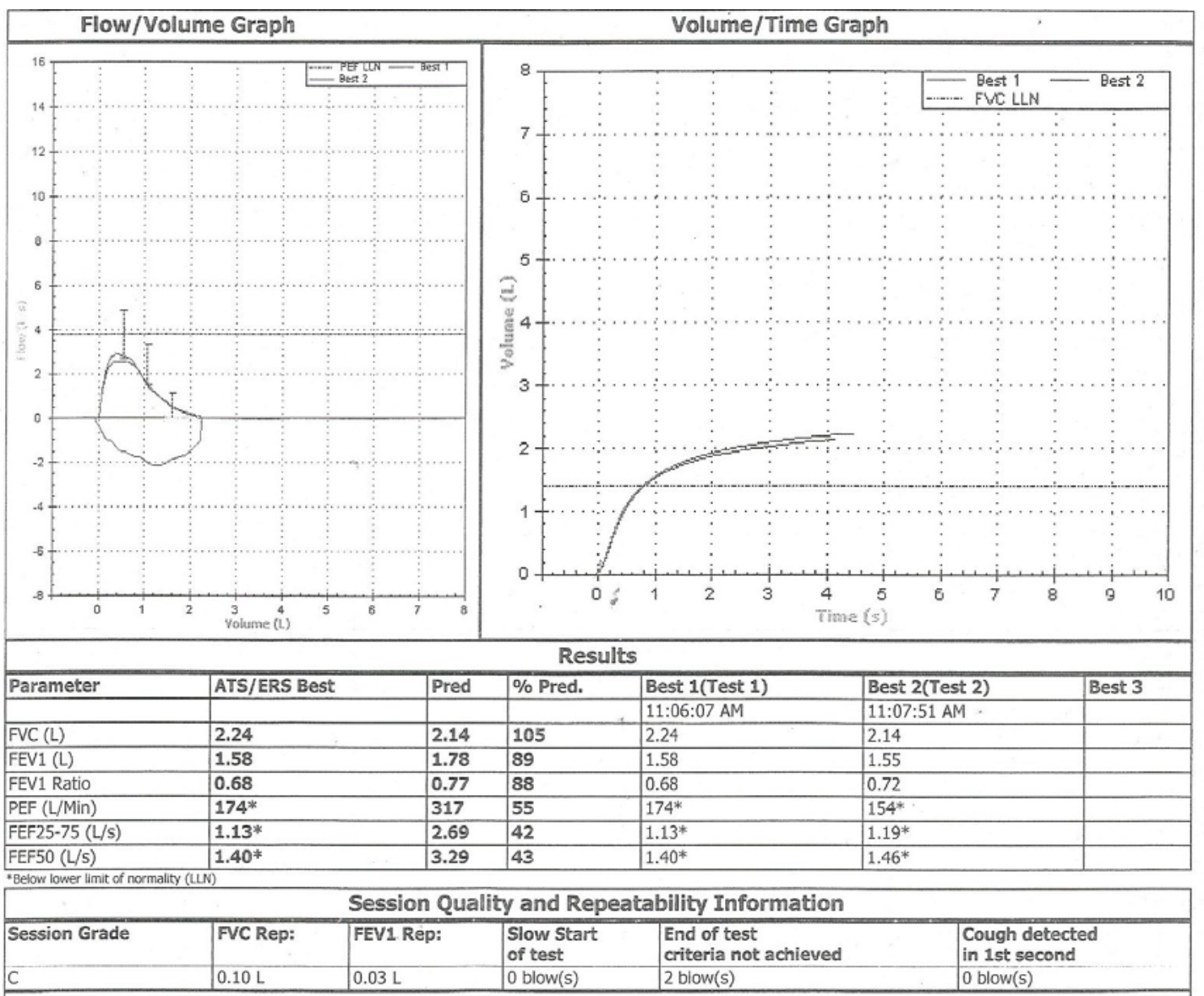

Figure 2. Pulmonary function report

\section{Conclusions}

This case describes a rare association in the third age in literature, namely the association of CD with ischemic cardiomyopathy. We also believe that besides dietary support, the psychiatric examination should be part of the evaluation of CD patients.

\section{References}

[1] Maxim R, Pleşa A, Ciortescu I, Gîrleanu I, Stoica O, Trifan AV. Celiac disease: 10-year experience in a Romanian tertiary center. Rev Med Chir Soc Med Nat Iasi. 2014;118: 986-991.

[2] Hvas CL, Jensen MD, Reimer MC, Riis LB, Rumessen JJ, Skovbjerg H, Teisner A, Wildt S1. Celiac disease: diagnosis and treatment. Dan Med J. 2015;61:C5051.

[3] Samasca G, Sur G, Lupan I. Deleanu D. Gluten-free diet and quality of life in celiac disease. Gastroenterology and Hepatology from bed to bench 2014;7:139-143.

[4] Samaşca G, Sur G, Lupan I. Current trends and investigative developments in celiac disease. Immunol Invest. 2013;42:273-284.
[5] Lupan I, Sur G, Deleanu D, Cristea V, Samasca G, Makovicky P. Celiac disease microbiota and its applications. Annals of Microbiology 2014;64:899-903.

[6] Castillo-Duran C, Pacheco-Acosta J. New Insights into Celiac Disease and Micronutrient Deficiencies in Pediatrics. International Journal of Celiac Disease. 2014;2:119-120.

[7] Milisavljević N, Cvetković M, Nikolić G, Filipović B, Milinić N. Dilated cardiomyopathy associated with celiac disease: case report and literature review. Srp Arh Celok Lek. 2012;140:641-643.

[8] Poddar B, Shava U, Srivastava A, Kapoor A. Severe heart failure, dilated cardiomyopathy and pulmonary haemosiderosis in coeliac disease: report of two cases. Paediatr Int Child Health. 2014;34:142-144.

[9] Lerner A, Matthias T. Celiac Disease: Intestinal, Heart and Skin Interconnections. International Journal of Celiac Disease. 2015;3:28-30.

[10] Jackson J. R, Eaton W. W, Cascella N. G, Fasano A, Kelly D. L. Neurologic and Psychiatric Manifestations of Celiac Disease and Gluten Sensitivity. Psychiatr Q. 2012;83:1-102.

[11] Małgorzata Urban - Kowalczyk. Psychiatric Complications of Celiac Disease. International Journal of Celiac Disease. 2015;3:25-27.

[12] Ludvigsson JF, Reutfors J, Osby U, Ekbom A, Montgomery SM. Celiac disease and risk of mood disorders - a general population based cohort study. J Affect Disord 2007;99:117-126. 